\title{
岂 Un viaje a través del tiempo: El proyecto Catherwood de Leandro Katz
}

\author{
Beatriz Cortez \\ California State University, Northridge
}

Mi objetivo para este ensayo es abordar las monumentales obras de arte y arquitectura que crearon los antiguos mayas en los períodos clásico y posclásico, pero también los diálogos visuales que estas obras han engendrado en dos artistas: Fredrick Catherwood en el siglo XIX y Leandro Katz en las últimas décadas del siglo $X X$ y a inicios de este siglo.

Fredrick Catherwood creció en Inglaterra, en un mundo heredero de la Ilustración en el que se celebraba el surgimiento de nuevas tecnologías e invenciones, pero también en un contexto parte de una empresa colonial que se consideraba con derecho a explorar, conquistar, extraer los recursos naturales y culturales de diversos países alrededor del mundo. Fue así que - de 1839 a 1840- Catherwood viajó por Centroamérica en calidad de explorador y artista. Había sido contratado por el explorador estadounidense John Lloyd Stephens para que lo acompañara en su viaje por Centroamérica y Yucatán, y creara ilustraciones del trayecto y, particularmente, de las pirámides mayas que habían sido abandonadas en la selva. Sus espectaculares dibujos fueron elaborados en los diferentes sitios mayas con tecnología moderna de su época. Catherwood utilizaba un dispositivo llamado cámara lúcida, un aparato con espejos que permitía proyectar y trazar una imagen exterior sobre la superficie plana del dibujo (Myers, 1972, p. 20). Este dispositivo había sido patentado en 1807 por William Hyde Wollaston (Davenport, 1991, p. 6), pero en realidad había sido imaginado mucho antes por el científico Johannes Kepler, allá por el año 1611 (Hammond y Austin, 1987, p. 16). Este aparato hacía posible a Catherwood ver lo que podría considerarse una imagen doble, es decir, ver la imagen de la pirámide sobre el papel, lo cual le permitía crear unos dibujos con grandes niveles de exactitud. Sus dibujos 
fueron después transformados en grabados y litografías que fueron publicados junto con los textos de Stephens. Como podría esperarse, la circulación de este libro generó gran interés por las culturas mayas entre estudiosos y arqueólogos en Harvard, Oxford y la Sorbonne, entre otros. Pero me interesa mucho más discutir la respuesta que generó entre un artista de origen argentino, y de inclinación más bien latinoamericana, más de 140 años después de la publicación del libro Incidents of Travel through Yucatán and Central América de Stephens y Catherwood. Fue por otros motivos lejanos al concepto de explorador y más afines al concepto de arte contemporáneo, del cine, y de un espíritu internacionalista, que Katz se dedicó a viajar de forma extensa por toda Latinoamérica y que en las décadas de los años 80 y 90 del siglo XX se embarcó en la tarea de capturar con el lente de su cámara las imágenes que originalmente había plasmado Catherwood.

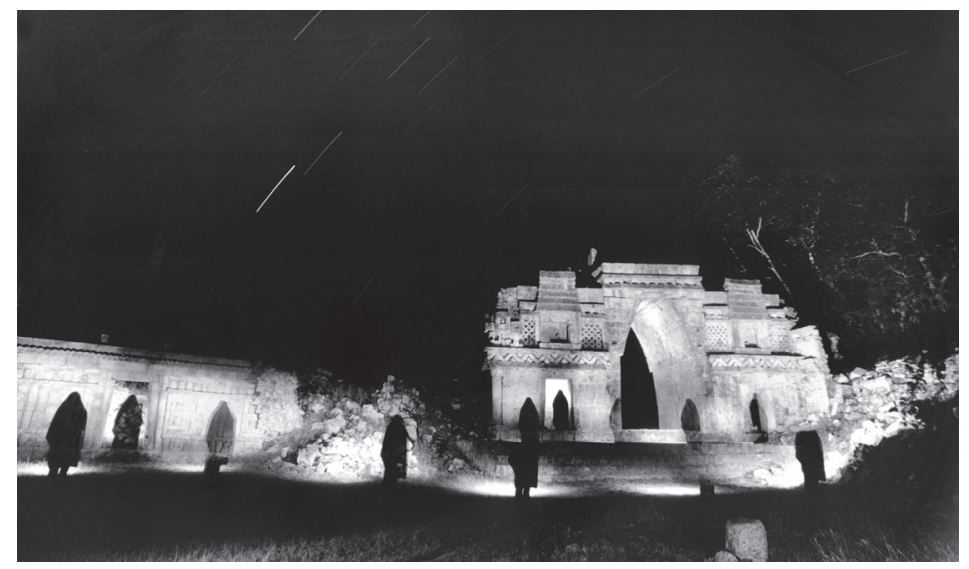

Puerta de Labná, ritual para el tiempo. Fotografía de Leandro Katz.

La técnica de la cámara lúcida que utilizaba Catherwood para elaborar sus dibujos, al igual que la fotografía, requiere enmarcar una imagen, lo cual conlleva sentidos estéticos pero también conceptuales. Por consiguiente, no es una labor fácil la de buscar reproducir un mismo punto de vista, la misma elevación, la misma iluminación generada por un artista del dibujo con el lente de una cámara. Llegar a cada espacio permitió a Leandro Katz pensar en posibilidades para lograr retratar no solamente las pirámides, templos y construcciones monumentales de los mayas, sino también retratar la mirada de Catherwood.

Me interesa aquí abordar un desacuerdo crítico sobre la fotografía 
que tuvo lugar entre los escritos de Judith Butler y Susan Sontag. Para Sontag (1977), una fotografía no es una interpretación, no tiene el poder de construir una interpretación, sino que para ella es "una emanación (olas de luz reflejadas por los objetos), un vestigio material del sujeto" (p. 154, la traducción es mía). Para Sontag, la fotografía es interpretada con base al texto en el pie de foto que acompaña a la imagen, es decir, con base a la narración de un contexto que necesariamente deberá ser presentado a través de la palabra para que pueda entenderse el sentido de la fotografía (Butler, 2005, p. 823). Butler se expresa en desacuerdo con esta idea e indica que el lenguaje visual puede funcionar de forma independiente de los textos en el pie de foto que lo acompañan o rodean, y que las imágenes construyen y pueden construir y participar en el discurso del lenguaje visual. Por lo tanto, Butler no solamente argumenta que la fotografía construye una interpretación, sino que se interesa también por las limitaciones técnicas, logísticas y políticas que impactan la forma en que se enmarca una imagen. Esto es todavía más crucial -indica Butler- en el caso de los fotógrafos que se encuentran inmersos en el frente de guerra como parte de la labor del Departamento de Estado de los Estados Unidos y, particularmente, después del ataque del 11 de septiembre. $Y$ ante esa realidad, ella expresa:

Podemos incluso decir que la conciencia política que mueve al fotógrafo a aceptar esas restricciones y a ceder a una fotografía que acata estos mandatos esta inmersa en el marco mismo. No tenemos que tener un texto al pie de la imagen ni una labor narrativa para comprender que un trasfondo político se está formulando de forma explícita y se está renovando a través del marco, -dice. Y continúa-: En este sentido, el marco tiene lugar en la interpretación de la guerra forzada por el estado; no es solamente una imagen visual que espera interpretación: está en sí misma interpretando, de forma activa, incluso a la fuerza. (Butler, 2005, p. 823, la traducción es mía).

Como resultado, indica que "llegamos a una interpretación que nos ha sido impuesta" (Butler, 2005, p. 824, la traducción es mía). Es así que Butler está interesada en estar alerta a las formas en que el estado opera sobre el campo de la percepción y, más generalmente, en el campo de la representación, a través no solamente de la imagen, sino también de la interpretación que compele el marco visual que enmarca esa imagen (p. 827). En otras palabras, para Butler, las 
fotografías no son inocentes objetos o enmarques que ocurren por casualidad. Para ella, un marco que es impuesto, delineado, diagramado es una operación del poder que se vuelve invisible. Necesariamente necesita permanecer invisible para poder ser una operación efectiva, como sucede con otras formas de poder. Por el contrario, ella explica que es presentada como un mapa, como una directiva, como una posición, como un protocolo. Para Butler (2005), este marco funciona como un aparato que crea una escena, como otra forma de ejercer el poder del estado y "aprender a ver el marco que nos ciega a lo que vemos no es fácil", señala (p. 826, la traducción es mía). En su libro Frames of War, Butler va más allá de la discusión sobre la fotografía de los medios al señalar que esta discusión puede ampliarse a otros espacios más allá del periodismo visual para considerar los enmarques, la forma que racializan o que conllevan un discurso civilizatorio sobre lo que consideran la realidad.

Esto tiene gran relevancia para la discusión que me interesa, pues antes del poder del Estado moderno estaba también el poder del colonialismo, y no está de más preguntarse si tras de los enmarques de los hermosos grabados basados en la obra de Catherwood no se reproduce también una invitación a compartir y reproducir un deseo colonial. No está de más considerar que estos dibujos llevaron a generaciones de arqueólogos a soñar con la nobleza y con los reyes mayas, con encontrar sus secretas tumbas, con poseer sus secretos y romper sus códigos, es decir, con poseer el poder de definir a los antiguos mayas mientras ignoraban a los mayas contemporáneos de su época.

En el caso de Leandro Katz, fuera del marco de cada imagen hay una enorme labor por lograr capturar, o lograr ver, con otra tecnología, con otro tipo de sistema óptico, la misma imagen capturada por Catherwood en aquel entonces. Lo que no se reproduce es el enmarque de la mirada colonial, como lo he dicho antes, sus motivos son otros que abren espacios para comprender desde otra perspectiva, no solamente la mirada de Catherwood, sino la fotografía misma. Lo cierto es que ni Fredrick Catherwood, ni yo, pudimos nunca imaginar que Leandro Katz al producir sus fotografías de El Proyecto Catherwood estaría generando una nueva serie en conversación con la obra de Catherwood, pero a la vez, estaría interviniendo una imagen que fue producida con gran detalle y exactitud 100 años antes del nacimiento del propio Leandro Katz. Digo que no sólo genera una nueva versión de estas obras, sino que además transforma para siempre nuestras formas de ver la obra de Catherwood. Lo cierto es que ya no puedo mirar los grabados basados en los dibujos 
que Catherwood hizo a mediados del siglo XIX sin ver la figura de Leandro Katz en ellos, dibujada por la mano de Catherwood más de 100 años antes, atravesando a finales del siglo XX una imagen creada a inicios del siglo XIX.

Ciertamente, la figura de Leandro Katz cubierta por un manto negro se asemeja a un arco maya, especialmente cuando contemplo las representaciones del arco de Labná. Es un verdadero viaje en el tiempo. Leandro Katz no solamente ha divisado una manera de capturar el movimiento y de fotografiar intersticios que existen en la cuenta larga y la cuenta corta del tiempo; ha logrado además intervenir imágenes bidimensionales y estáticas, transformarlas, habitarlas.

En Copán-Ritual para un tiempo transfigurado, Katz no sólo interviene la imagen de Catherwood sino que interviene una obra de arte todavía más antigua: la construcción arquitectónica de los mayas. Así, inserta numerosos arcos donde no existen, arcos temporales, gestualidades de arcos, posibles arcos, arcos en movimiento, su propia imagen atravesando el espacio con un flash portátil. Es decir: dejaba abierto el obturador mientras en la oscuridad se movía a través de la pirámide, iluminando cada sección con la luz de un flash.

Copán, ritual para el tiempo. Fotografía de Leandro Katz.

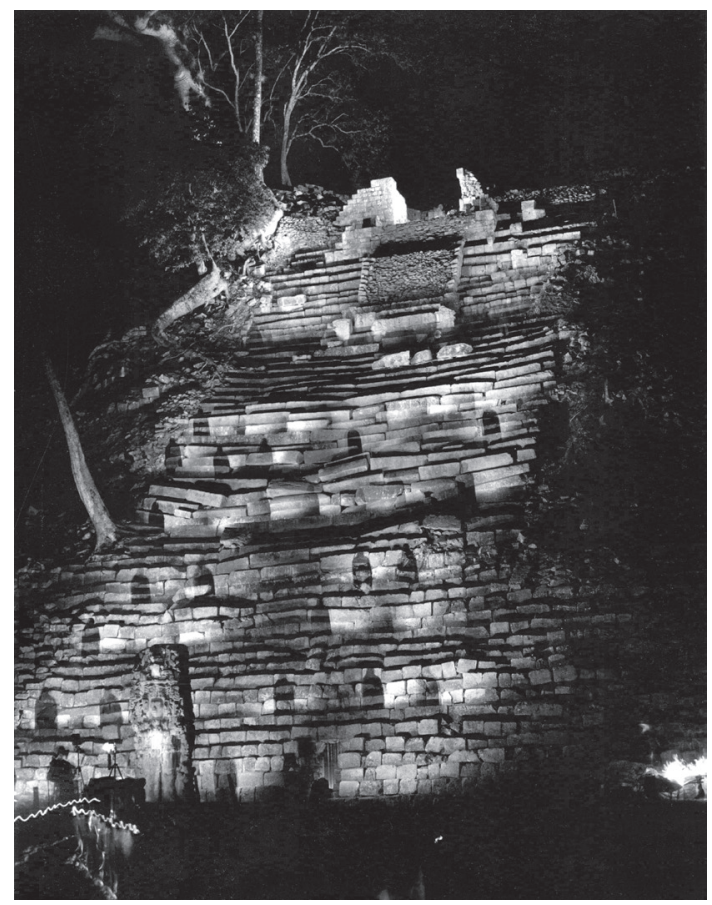


Pero hay tantas capas en las intervenciones. Esta obra - realizada en una década de viajes - desmantela algunas de las ideas que han sido tomadas por ciertas en el pensamiento occidental. Por ejemplo, cómo no pensar en las reflexiones plasmadas en un libro precisamente con el título de Cámara lúcida: una nota sobre la fotografía, que hacía Roland Barthes ante una fotografía de su madre cuando era niña, pero las hacía en un momento en que su madre acababa de fallecer. Decía Barthes entonces, al respecto de la cualidad fija de una fotografía y de sus dos dimensiones, que toda fotografía es desde siempre la imagen de un cadáver. Es decir, el momento que captura es un momento que ya nunca podrá recuperarse. Sin embargo, ante las fotografías de El Proyecto Catherwood de Leandro Katz, pienso en el movimiento que captura esta imagen, en las diferentes temporalidades que evoca, en los diferentes intersticios que están plasmados en cada una de estas fotografías.

En la cosmovisión maya existe una cuenta corta y una cuenta larga de los días, estas diferentes cuentas transcurren de manera simultánea capturando el movimiento imparable del tiempo en su devenir. Los mayas, como Gilles Deleuze también lo hizo mucho después, expresan sus ideas sobre el perpetuo movimiento y el constante devenir. De manera paralela, en la obra de Leandro Katz se captura la existencia de intersticios cortos e intersticios largos en el tiempo. Unos duran unos minutos, tal vez unas horas entre uno y otro. Son parte de una misma fotografía capturada por segmentos gracias al movimiento del fotógrafo y a la intervención del flash. Estos intersticios capturan su movimiento en la oscuridad de las pirámides. Entre una y otra acción del flash queda un intersticio, la trayectoria que llevó a la figura del fotógrafo a moverse de uno a otro espacio. No se trata -como alguna vez dijo Judith Butler- de performance, o de una representación de la identidad que se repite de manera compulsiva, una performance que corre el riesgo de resquebrajarse en el breve intersticio entre una y otra repetición compulsiva de la identidad (Butler, 1996). Como lo examina también Homi Bhabha en The Imitation of Culture, los intersticios no son solamente vacíos, son posibilidades. En la filosofía especulativa que se abre campo en el cuestionamiento del humanismo y el devenir de la filosofía occidental se explora la posibilidad de especular ante este intersticio o este vacío que existe entre una y otra repetición de la presencia de lo humano. Por un lado, entre la figura plasmada del artista y la siguiente no podemos sino especular; ¿cuánto habrá tardado en llegar a su siguiente aparición ante el flash?, ¿qué dificultades habrá tenido para moverse en la oscuridad?, ¿qué habrá pensado?, ¿dudaba?, ¿sentía vértigo?, ¿miraba 
las estrellas?, ¿soñaba? Por otro lado, ese vacío, la ausencia del ser humano, su inmaterialidad, nos invita a especular en posibilidades poshumanas, o no humanas, como diría Claire
Colebrook, nos invita a imaginarnos un mundo sin nosotros, o para tomar prestadas las palabras de Deleuze, a imaginarnos esta obra de arte como si su espectador todavía no existiera.

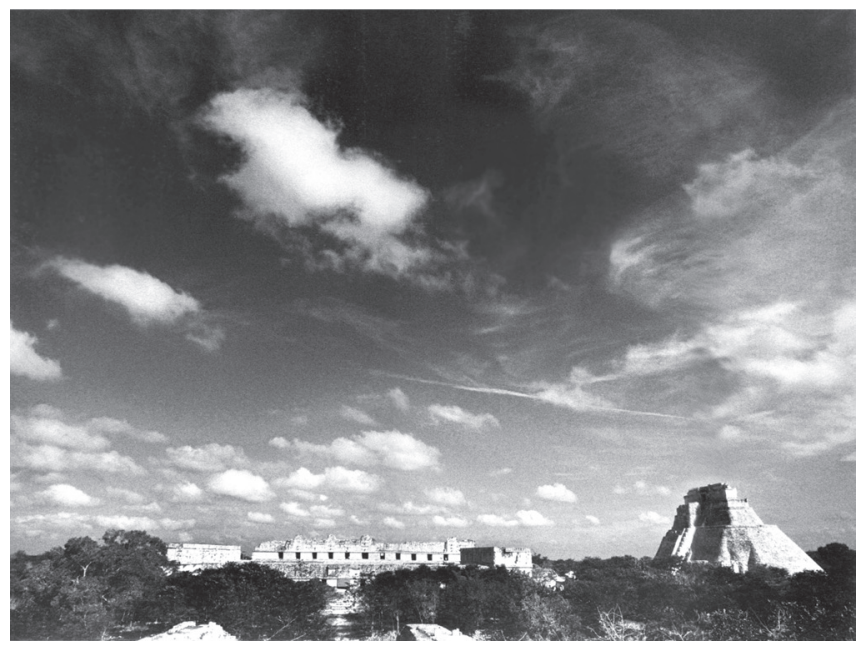

Casa de las monjas y casa del enano. Fotografía de Leandro Katz

Pero, hay otros intersticios. La cuenta larga de los intersticios que captura la obra de Leandro Katz la marca la aparición de esta misma imagen en la obra de Catherwood y más de un siglo más tarde, la reaparición de la imagen en la obra de Katz. ¿Cuántas muchedumbres habrán pasado por estos mismos espacios y habrán seguido esas mismas trayectorias que Catherwood y que Katz?, ¿qué movimientos seguían?, ¿qué hacían?, ¿eran turistas?, ¿peregrinos?, ¿creyentes?, ¿escapaban de la modernidad a través de este portal como lo busco hacer yo ahora a través del pensamiento especulativo y ante la obra de Leandro Katz? Este intersticio marca el espacio que existe entre dos tecnologías, un mundo sin cámaras mecánicas pero con cámaras obscuras y cámaras lúcidas, un mundo donde la fotografía análoga ya se ha vuelto obsoleta aunque es -como lo demuestra Katz- irremplazable, pues este proceso creado por él no es posible con la fotografía digital. Sólo el film le permite intervenir de esta manera en el tiempo, capturar sus movimientos y también las diferentes temporalidades, dejar evidencia que entre una y la siguiente repetición de nuestra existencia hay intersticios breves y largos, invitaciones a especular, portales a otras perspectivas, polvo cósmico, desarticulación del ser humano, porosidades dibujadas 
por la densidad del aire, del tiempo y del espacio.

Hay, sin embargo, un intersticio todavía más largo que se marca entre la construcción de este templo y la intervención de Katz. En ese intersticio ahora borroso, dibujado únicamente por ausencias, ocurrió algo que desde la perspectiva larga del tiempo no fue sino una breve pausa de la luz de un flash: el humanismo, el liberalismo, la ilustración, el pensamiento racional. Pero si la cuenta del tiempo no se equivoca, fue solamente un breve intersticio.

\section{Referencias}

- Barthes, R. (1992). Camera Lúcida: Reflections on Photography. (Trans. Richard Howard). New York: Hill \& Wang.

- Bhabha, H. (1994).The Location of Culture. New York: Routledge.

- Butler, J. (1996). Immitation and Gender Insubordination. The Material Queer: A Lesbigay Cultural Studies Reader. Ed. Donald Morton. Pp. 180-192. . (2005). Photography, War, Outrage. PMLA 120.3 pp. 822-827. . (2009). Frames of War: When Is Life Grievable? London: Verso.

- Colebrook, C. (2014). Death of the Posthuman: Essays on Extinction, Vol. 1. Ann Arbor: Open Humanities Press.

- Davenport,A.(1991). The History of Photography:An Overview. Albuquerque: University of New Mexico Press.

- Deleuze, G. (1994). Difference and Repetition. (Trans. Paul Patton). New York: Colombia University Press. . (1986). Nomadology: The War Machine. New York: Semiotext(e).

- Hammond, J. \& Jill Austin. (1987). The Camera Lucida in Art and Science. New York: Taylor \& Francis.

- Katz, L. (1985-1995, 2001). The Catherwood Project. Films, photographs, books, and installations.

- Kepler, J. (1611). Dioptrice. Prague.

- Myers, V. A. (1972). Friederick Catherwood: Engravings and Lithographs from the Mayan Drawings. Books at lowa 16. Pp. 14-33.

- Sontag, S. (1977). On Photography. New York: Picador.

. (2003). Regarding the Pain of Others. New York: Picador.

- Stephens,J. L. \& Fredrick Catherwood. (1843). Incidents of Travel in Yucatan. New York: Harper \& Bros. . (1841). Incidents of Travel in Central America, Chiapas, and Yucatan. New York: Harper \& Bros. 